\title{
Aromatase deficiency
}

INSERM

\section{Source}

INSERM. (1999). Orphanet: an online rare disease and orphan drug data base. Aromatase deficiency. ORPHA:91

Aromatase deficiency disrupts the synthesis of estradiol, resulting in hirsutism of mothers during gestation of an affected child; pseudohermaphroditism and virilization in women; and tall stature, osteoporosis and obesity in men. 